RESEÑA

\title{
JÓVENES EN BUSCA DE RESPETO
}

\author{
por ERNESTO MECCIA ${ }^{1}$
}

\section{Pablo Francisco Di Leo y Ana Clara Camarotti (directores): Individuación y reconocimiento. Experiencias de jóvenes en la sociedad actual. Buenos} Aires, Teseo, 2015, 368 pp. ISBN 9789877230611. Disponible on line en: https://goo.gl/CVrcrp

“Individuación y reconocimiento. Experiencias de jóvenes en la sociedad actual” es una recomendable compilación en la que sus directores ahondan en apuestas conceptuales y metodológicas aplicadas al estudio de las experiencias de los jóvenes de sectores populares. Desde la primera hasta la última página se nota lo conscientes que están de las dinámicas estructurales de la desigualdad y la vulnerabilidad social. Pero también se nota -es más, la apuesta es notoriaque quieren estudiarlas desde el punto de vista de los actores sociales. En mi opinión, algo mil veces prometido pero pocas veces tan cumplido como aquí, en los libros de Ciencias Sociales. Consecuentemente, lo que vemos en “Individuación y reconocimiento” son actores jóvenes que se topan y reconocen estructuras y dificultades objetivas (materiales y simbólicas) pero que también hacen miles de cosas (materiales y simbólicas) para tratar de vivir mejor. Los actores son realmente los protagonistas del libro; lo cual es indicador de un convencimiento ético que tienen estos estudiosos respecto de una de las funciones de la investigación en ciencias sociales: dar voz y ver el mundo a través de sus hacedores, cuyas palabras caen con frecuencia en los dominios de

${ }^{1}$ Doctor en Ciencias Sociales, Magíster en Investigación en Ciencias Sociales y Licenciado en Sociología por la Universidad de Buenos Aires. Profesor ordinario de grado y posgrado en la UBA y la Universidad Nacional del Litoral. 
la ilegitimidad dictada por el orden cognitivo-moral dominante. El recurso elegido para ver la vulnerabilidad desde adentro son los “relatos” de los actores, sus historias de vida. Y allí, sobre esa realidad discursiva que es un relato, podemos observar una doble presencia: la del mundo que se mete en los sujetos poniendo dificultades en el camino, y la de los sujetos que le cuentan a los entrevistadores las cosas que le hacen o que le quieren hacer a ese mundo que los restringe vitalmente. En el libro hay estructuras sociales de gran y temerario peso, sin duda. Pero no hay aplastados ni vencidos. Hay gente joven que hace, que efectúa, que imagina y sueña.

En la introducción, Pablo Di Leo y Ana Clara Camarotti, hacen una presentación de los grandes lineamientos epistemológicos y conceptuales del libro. Se proponen trabajar sobre vulnerabilidad y experiencia en la línea de François Delor y Michel Hubert, desplazando el eje analítico desde las situaciones hacia los procesos, para indagar empíricamente las vinculaciones entre lo individual y lo social a partir de tres niveles de experiencia biográfica: las trayectorias personales, los vínculos e interacciones y los contextos socioinstitucionales. Interesante: lo contextual no es una variable que actúa en un solo sentido, también es observada como algo que puede ser utilizado por los actores en sus búsquedas de recursos materiales, afectivos o simbólicos. Asimismo, Francois Dubet y Danilo Martucelli integran las directrices conceptuales de la obra. A través de ellos, los compiladores destacan que la experiencia social es el emergente del ensamblado entre tres lógicas de acción: la integrativa, la estratégica y la subjetiva. La primera alude al modo de la interiorización de lo social, la segunda a las formas de interacción y movilización de recursos en contextos particulares y la tercera a las definiciones que hacen de sí mismos los sujetos.

En el capítulo de Sebastián Ezequiel Sustas "Estar juntos como prueba: tensiones en las relaciones de pareja juveniles” se indaga las tres caras de la prueba de pareja: primero la “iniciación” -que refiere a las primeras 
ritualidades afectivas que puede incluir la iniciación sexual-, el “crédito”-que apunta a las dinámicas de legitimación de la pareja a partir de las miradas y expectativas de los entornos-, y finalmente la “convivencia”-que remite a las experiencias de cohabitación. Es para prestar atención la noción de “crédito”, es decir, la percepción -sin duda basada en valores- sobre la perdurabilidad de las parejas realizadas por personas que pertenecen a otras generaciones. Es más que probable que los evaluadores posean otros criterios referidos a la temporalidad del estar juntos y, probablemente, otra concepción de la pareja en sí misma. Tal vez lo que ellos observan cuando otorgan más o menos crédito son desplazados- sus propios vínculos de pareja, distintos a los de las parejas evaluadas, ya que es probable que manejen otros indicadores de proyección. En estos temas, hoy en día, la cercanía generacional no evita esas disonancias cognitivas y valorativas.

María Soledad Vázquez es la autora de "Integración, estrategia y subjetivación: biografías escolares y experiencias de maternidad”. Toma las historias de María Paula y Juana para trazar una reflexión sobre las trayectorias educativas de jóvenes embarazadas y madres, tratando de ver cómo tratan de hacerse un lugar en los ámbitos educativos. Pone en evidencia que los recorridos escolares por el nivel secundario que no se ajustan a lo estipulado por el sistema tradicional son menos un indicador de “fracaso” que una expresión biográfica contemporánea de los modos que asume la experiencia escolar. El artículo sirve para pensar la estigmatización por pobreza y género. Las jóvenes van a establecimientos educativos especiales, relativamente adaptados a sus realidades. Son, como dice la autora, escuelas “más fáciles”. Y lo que puede ser un logro de política pública genera, sin embargo, miradas sociales reprobatorias que ve en lo “adaptado" o lo "facilitado" a los vulnerados un regalo y un exceso de protección; eso que Danilo Martucelli llama los “soportes estigmatizantes”, es decir, aquellos resortes que en principio ayudan a los individuos a vivir pero que al mismo tiempo sirven para descalificarlos y los convierten en seres sobrevisibilizados, habida cuenta de su extrema dependencia del entorno. De esta 
forma de ver las escuelas a la concepción ampliamente extendida sobre los planes sociales no hay siquiera un paso. En sociedades como las nuestras, si el individuo no se puede (sos)tener por sí mismo, no es un ser de valía, es una carga social.

Florencia D’Aloisio, Valentina Arce Castello y Horacio Luis Paulín escribieron "Hacer frente a la lógica escolar: demandas y expectativas de reconocimiento". También trabajaron con jóvenes cordobeses que se encuentran realizando la escuela secundaria; en este caso, para poner de relieve los ensayos cotidianos de busca de respeto y de reconocimiento y de sus ideas de horizontalidad y justicia en el contexto escolar. Una empresa nada fácil. Los autores traen de forma nítida planteos teóricos de Axel Honneth, Emilio Tenti Fanfani, Gabriel Kessler. El capítulo resulta atractivo. Dibujan los atributos educativos de los sujetos estudiados con una precisión que atemoriza: estos chicos son los últimos en llegar a la educación secundaria, pero los primeros en llegar en relación a sus progenitores y, como si fuera poco, los "recién llegados" mirados desde el status de un alumno modelo. Asimismo señalan las consecuencias negativas de aquellos escenarios escolares en los que no se reconoce al "joven” que hay en el "alumno", esto es, cuando se invisibiliza la diversidad sociocultural desde la que los jóvenes llegan a la escuela y se desenvuelven en ella.

Hay un capítulo de Ana Clara Camarotti sobre las "Experiencias comunitarias de cuidado y diversión en circuitos de música electrónica”. En forma inversa a las que se massmediatizan para la creación de pánicos morales, la autora se juega para mostrar el lado socialmente productivo, en un sentido casi durkheiminiano (que sin duda encuentra ecos en Michel Maffesoli) de las denominadas fiestas electrónicas. Por momentos, hasta parece encontrar la célebre formulación de Robert K. Merton sobre las "funciones latentes" de ciertos fenómenos, que representan -más allá de las cuestiones de superficie- el saldo positivo de estos eventos en términos de creación de lazos grupales. Tema de candente actualidad y desafiante para la teoría social, el consumo de las 
drogas de síntesis, tal como plantea Alain Ehrenberg, al igual que lo que ocurre con los medicamentos psicotrópicos, no debiera caracterizarse unilateralmente por la desocialización y la decadencia; la caracterización también debiera incluir efectos de socialización en contextos donde son escasos los recursos "para sentirse mejor”; de ahí su alto nivel de tolerancia social.

En "Entre nosotros nos cuidamos siempre”: consumos de drogas y prácticas de cuidado en espacios recreativos nocturnos”, Martín Guelman se queda en ese tema urticante. El título y el subtítulo son claros. Abreva en Betina Freidin para justificar su elección metodológica (los grupos focales). Dice que aplicando esta técnica se crean situaciones de interacción social particularmente fértiles para observar cómo las personas en sus redes de interacción y círculos gestionan diferentes prácticas de cuidado, aceptando algunas y cuestionando otras, significando permanentemente sus decisiones. Guelman respalda con información sus afirmaciones, por ejemplo, la que dice que, a diferencia del enfoque enraizado en la noción de grupo de riesgo, el paradigma basado en el concepto de procesos de vulnerabilidad permite trabajar con poblaciones históricamente excluidas de la investigación e intervención sanitaria, como son los jóvenes de sectores medios. Los interesados en el interaccionismo simbólico -por su parte- pueden encontrar en este capítulo una meritoria aplicación, en particular, en los tramos en los que el autor cuenta el logro paulatino por parte de los jóvenes de la expertise en torno la ingesta de sustancias y a los cuidados concomitantes, vía la incorporación de los códigos grupales.

En “¿Sucios, feos y malos?: experiencias de jóvenes en tratamientos por consumo de pasta base/paco", de Romina Ramírez se estudian relatos para analizar el recorrido que la mayoría de los entrevistados vivieron cuando intentaron ser atendidos. Sólido artículo que construye una visión del revés de la trama. ¿Por qué? Porque las narraciones permiten derribar el mito -en gran parte massmediático- que sostiene que los usuarios de pasta base/paco no piden ayuda. Se observa que los entrevistados buscaron ser atendidos, pero pocas 
veces fueron escuchados desde sus particulares situaciones. Repárese, por ejemplo, en el caso de una muchacha embarazada que quiere salir del consumo: recibe por parte de la institución médica un trato comparativamente "cordial" pero no por su problema con las sustancias sino debido a su embarazo. En los otros casos, las distancias simbólicas que interpone la institución son mucho más profundas, al punto que delinean un diálogo de sordos, donde nadie sabe nada del otro. Las narraciones no sólo dan cuenta de la falta de preparación de los efectores de salud, sino también de la ausencia de protocolos, acuerdos, arreglos y normativas institucionales existente en los hospitales para trabajar con los usuarios de pasta base/paco. Y ello a pesar de la vigencia de la Ley Nacional del Salud Mental.

En “Caer detenido”: Vulnerabilidades punitivas y trayectorias penalizadas”, Natalia Laura González y Paula Andrea Trillo -inspiradas en los valiosos trabajos de Alcira Daroqui- exponen desde los relatos de las experiencias de los sujetos, una especie de círculo vicioso que se da en personas en situación de vulnerabilidad que pasan por procesos judiciales y encarcelamiento. Daroqui se refiere así a una “cadena punitiva”, un auténtico imán de cuya fuerza se hace muy difícil sustraerse. Las autoras sostienen que, en tanto procesos sociales e individuales, estos procesos se colocan en las intersecciones que se generan entre las trayectorias individuales penalizadas, los vínculos e interacciones debilitados por el encierro y los contextos socio-institucionales internos y externos a la institución carcelaria. Estos contextos son el marco fundamental que ubica a estos jóvenes marginalizados en un continuum que los reenvía una y otra vez a situaciones de violencias. Artículo denso y multidimensional, constituye un ejemplo dramático de cómo el viejo concepto de "carrera” sigue siendo útil en la sociología.

"Los pibes tienen muchos berretines": muertes entre jóvenes, contextos de experiencia y reconstrucciones biográficas” de Alejandro Marcelo Villa es un escrito de alto impacto que, además del tema intrínseco, toca cuestiones muy 
interesantes desde el punto de vista teórico de las ciencias sociales como el significado del duelo y la gestión del honor y la reputación del muerto en el contexto barrial. En este trabajo -nos cuenta el autor- se seleccionan los principales repertorios culturales que utilizan los actores para construir una reputación del muerto y de sus familias. Estos repertorios pueden entenderse como una estantería de categorías a las que recurren los actores para clasificar una situación social específica. Dichas categorías son modos de actuar que permiten una lectura de las formas en las que somos socializados; y en las que se ponen en tensión los significados para uno y para el otro. Tal vez lo más interesante sea el enmarque "cognitivo-moral" que hace el autor de la violencia y de la muerte. Se pregunta: ¿qué demanda de creación de sentidos inaugura la muerte de un joven? ¿qué valores entran en disputa para hacer inteligible ese acontecimiento? ¿qué significa para los familiares que siguen viviendo en el barrio hacerse moralmente responsables del joven muerto? Mientras se lee el capítulo es imposible no recordar "Cuando me muera quiero que me toquen cumbia”, de Cristian Alarcón. Como aditamento, Blanco nos trae a una conceptuosa Judith Butler, en este caso no consultada por sus estudios de género, sino por su libro "Vida precaria. El poder del duelo y la violencia”.

El libro da un giro decidido hacia la sociología urbana desde una perspectiva fenomenológica con Guido García Bastán y Horacio Luis Paulín, autores de "Hacerse joven en la ciudad: dinámicas urbanas y construcción de identidades". El lector se encontrará con una reflexión pegadiza sobre los escenarios de periferización urbana actual, escenarios que son el emergente -por supuesto- de las delimitaciones geográficas pero -he aquí el aporte- también de sus imbricaciones con demarcaciones morales y emocionales que los jóvenes aplican sobre sí mismos y sobre los seres de la gran urbe. García Bastán y Paulín hacen tomar nota acerca de que la referencialidad urbana de los actores depende en mayor medida de sus "mapas subjetivos" (en todo momento dinámicos) que de estáticas (y antiguas) coordenadas geo-referenciales. Pensando en los jóvenes de sectores populares en condiciones de periferización, 
su auto-referencia residencial puede funcionar como un "soporte estigmatizante” (aparece nuevamente el concepto de Danilo Martucelli). Es decir: el barrio es al mismo tiempo la contención identitaria y la fuente del estigma. En estas condiciones los jóvenes deberán operar (contrasimbólicamente) para convertirlo en sostén y aminorar la discriminación de la que serán objeto en su pasaje por distintos escenarios institucionales.

Silvia Alejandra Tapia es la autora de "De límites a estrategias: movilidades de jóvenes que realizan actividades artísticas y deportivas”. Preocupada por la segregación socio-espacial, la autora plantea haciéndose eco de la reflexión de Ramiro Segura la necesidad de estudiar los sectores populares más allá de su cotidianeidad barrial. Se da entonces la tarea de comprender las lógicas de circulación de los jóvenes de sectores populares por la ciudad y el encuentro con otros actores sociales, para poner en cuestión las concepciones de vida urbana que parten sólo de la separación y el aislamiento. Es mejor seguir las huellas que van dejando los jóvenes transeúntes; de ellas saldrán buenas lecciones de sociología urbana. No se niega la lógica de la guetización pero, como el agua, quienes viven dentro de ciertas condiciones, ocupan otros lugares ni bien comienzan a deslizarse. En este sentido, resultó atractivo para Tapia observar las características y el sentido que adquieren las movilidades urbanas cotidianas en las biografías de jóvenes que realizan actividades artísticas y deportivas en espacios gratuitos de la Ciudad de Buenos Aires, los modos en que se limitan o regulan tales movilidades así como las estrategias desplegadas para atravesarlas.

El libro cierra con otra entrega de los compiladores Pablo Francisco Di Leo y Ana Clara Camarotti, titulada "Todo puede, todo el tiempo, cambiar: (in)consistencias, agencias y procesos de individuación”. Aquí está el tema del que hablé al principio: la iniciativa a la que nos vemos compelidos los contemporáneos. Todas las posiciones pueden sufrir procesos de desestabilización, dicen Di Leo y Camarotti. Estos sentimientos plurales de 
inestabilidad se grafican en la expresión: todo puede, todo el tiempo, cambiar. A partir de allí vienen -aunque no siempre- los modos de reconfiguración subjetiva que tienen como duración el tiempo de una vida. No en vano Anthony Giddens, en contextos de alta modernidad sociológica, hablaba de la biografía como un proyecto reflejo del yo. Para los autores, el problema no es que los actores no "son" como los otros, sino que se perciben colectivamente como los "otros" y sienten que sus posiciones son particularmente inestables. Como estrategia para contrarrestar esta inestabilidad, los agentes buscan -a partir de su esfuerzo, habilidades personales y relacionales interpersonales- multiplicar sus recursos, vínculos o soportes con el fin de apuntalar y solidificar una posición social que sienten edificada sobre la arena.

Para cerrar, también invito a leer este libro porque nos da claras evidencias de que cuando se emprende un estudio con una clave conceptual y metodológica que fue debatida y consolidada por el equipo de investigación, la coordinación y la sistematización del trabajo de campo, al tener una razón de ser, facilita la aparición de resultados contundentes, como los que leí. 